\title{
ELECTRONIC VERSUS ATOMIC STRUCTURE IN LIQUIDS
}

\author{
W.H. Young \\ School of Mathematics and Physics, University of East Anglia, \\ Nomich NR4 7TJ, U.K. \\ Résumé - Un modèle de sphères dures correspond assez bien au facteur de struc- \\ ture $S(q)$ d'un 'métal liquide. L'addition d'une contribution attractive augmente \\ le $S(0)$ des sphères dures et modifie de façon négligeable les pics principaux. \\ Une contribution répulsive annule $S(0)$ et produit des anomalies aux grandes \\ valeurs de $q$. Ces résultats sont bien en accord avec les théories de pseudo- \\ potentiel. De plus, les modèles de mélange de sphères dures fournissent des \\ indications sur le $S_{c c}(q)$ des alliages. Des contributions supplémentaires in- \\ troduisent un potentiel d'ordre qui, s'il est attractif (ou répulsif), \\ augmente (ou diminue) $\mathrm{S}_{\mathrm{cc}}(\mathrm{o})$ par rapport à la valeur des sphères dures et il $\mathrm{y}$ \\ a tendance à une séparation de phase (formation de composés). Les théories \\ de pseudopotentiel s'appliquent formellement mais introduisent des contribu- \\ tions où se concentrent les potentiels d'ordre; les calculs ab initio sont \\ évidement risqués.

\begin{abstract}
Hard spheres provide a suitable reference fluid for liquid metal $\overline{S(q) ' s . ~ S u p p l e m e n t a r y ~ a t t r a c t i v e ~ t a i l s ~ e n h a n c e ~ t h e ~ h a r d ~ s p h e r e ~} S(0)$ and yields featureless principal peaks; repulsive tails suppress $S(0)$ and explain higher-q anomalies. These conclusions are consistent with NFE pseudopotential theory. Likewise, hard sphere mixtures provide insight into $S$ (q) for an alloy. Supplementary tails define an ordering potential which: if repulsive (attractive), means $S_{C}(0)$ is elevated (suppressed) relative to hard sphere values and there $1 \mathrm{C}$ a phase separating (compound formins) tendency. NFE pseudopotential theory formally applies but, even if valid, yields tails the inevitable errors in which accumulate in the ordering potential; ab initio calculation is evidently risky.
\end{abstract}

\section{I - INTRODUCTION} \\ The present paper, exceptionally at this conference on amorphous solids, concerns \\ liquids. It shows how observed structure factors broadly delineate interatomic \\ forces; this allows an assessment of how well the latter are specified by ab initio \\ electron theory. It is interesting to note that structure factors depend on the \\ full interatomic potentials in liquids and amorphous solids since all parts (exclud- \\ ind the impenetrable cores) are sampled and appear in the configurational averages. \\ Crystals, on the other hand, are characterised by staticlattice configurations and \\ those nearby accessible by thermal vibration and so cannot, in principle, provide as \\ much information. \\ Liquids and amorphous solids differ in that the former are in thermodynamic equilib- \\ rium whereas the latter are not. Thus, although the concept of the distribution \\ function is used in both cases, only in the former is it governed by the principles \\ of equilibrium statistical mechanics. This is of immense significance and help as \\ is seen below. \\ We consider monatomic and binary metallic systems only. The former are of consider- \\ able intrinsic interest, illustrate some general principles and are, therefore, con- \\ sidered first ( $(I I)$. Later, the binary problem is examined ( $(I I$ ) and a summary pre- \\ sented ( $\Sigma I V)$.
}

\section{II - MONATOMIC FLUIDS}

(i) Generalities

Consider a monatomic fluid of mean number density $n$. The radial distribution func- 
tion $g(r)$ is obtainable from the interatomic forces using statistical mechanics and connection with experiment is made via the structure factor

$$
S(q)=1+n \int\{g(r)-1\} \exp (i q \cdot \underset{\sim}{r}) d r .
$$

At long wavelengths, density fluctuation theory yields the identity

$$
S(0)=n k_{B} T k_{T}
$$

Here, $K_{T}$ is the isothermal compressibility and so $S(0)$ is measurable thermodynamically; it diverges as the critical point is approached.

The direct correlation function $c(r)$ is defined by the ornstein-Zernike (OZ) equation

$$
h(r)=c(r)+n \int h\left(\left|\underset{\sim}{r}-\underset{\sim}{r^{\prime}}\right|\right) c\left(r^{\prime}\right) d \underset{\sim}{\prime}
$$

where $h(r)=g(r)-1$. Alternatively, in Fourier transform, and using (1),

$$
s^{-1}(q)=1-n c(q) \text {. }
$$

The direct correlation function reflects closely the potential; if the latter is pairwise and given by $v(r)$, statistical mechanics yields

$$
\left.c(r) \sim-v(r) / k_{B} T \quad \text { (large } r\right)
$$

and experience suggests (5) is quite accurate anywhere outside the core. If $c(q)$ in (4) Taylor expands, we obtain the oz form

$$
S(q)=S(0) /\left(1+\xi^{2} q^{2}\right) \quad(l o w \quad q) \text {. }
$$

Near the critical point, the correlation length, $\xi$, indicates the size of the density fluctuations; near the triple point, often (always in metals?) $S^{\prime \prime}(0)>0$ with (formally) $\xi^{2}<0$.

Real fluids resemble, in zeroth order, hard sphere systems which have, therefore, been subject to much theoretical study. The results obtained will be drawn upon as required below.

\section{(ii) The alkalis; illustrative example of Rb}

Fig. 1 shows some observed structure factors /1/ for Rb. and their fit to hard sphere data. This is moderately satisfactory at large $q$ but incorrect for small q, high T. Evidently, (6) applies in the latter circumstances, hard spheres alone being inappropriate.

The problem is simply solved thus: (a) calculate $v(r)$ (at each density) using pseudopotential theory, (b) separate core and tail parts /2/ (Fig. 2), (c) approximate the cores by hard spheres. (d) treat the tails as perturbations. The core scarcely varies with density and one reads off effective diameters $\sigma$ using /4/ $v_{\text {core }}(\sigma) \approx k_{B} T$, the probing of the increasingly steep parts explaining the saturation noted in Fig. 1. The tails may be incorporated using the random phase approxmation (RPA) /5/

$$
c(r)=c_{\text {core }}(r)-n v_{\text {tail }}(r) / k_{B} T \text {, }
$$

which recognises basic core and tail aspects (eq. (5). Fourier transformation of (7) and use of (4) gives the Fig. 1 oz behaviour.

A reverse analysis is also possible $/ 6,7 /$; the observed $S(q)$ leads, using (4), to a $c(r)$ which, outside the core (cf. (5), (7)), yields a Fig. z tail. 


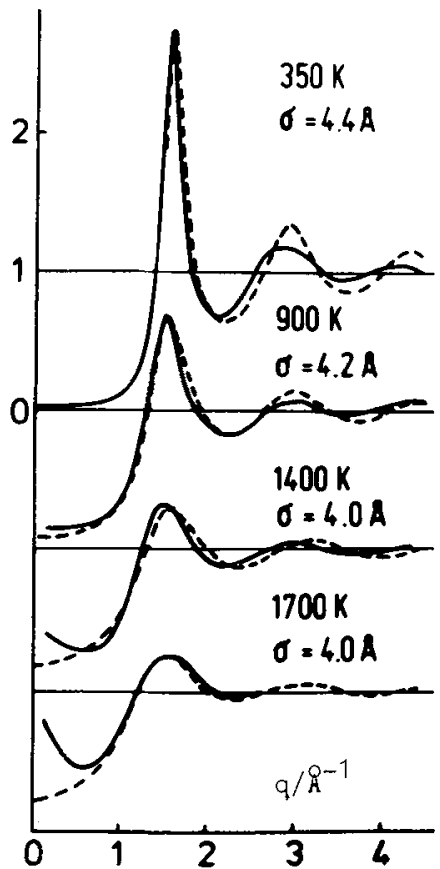

Fig. 1 - Observed (-) and hard sphere fits (--) for $S(q)$ for Rb near saturation.

(iii) Polyvalent metals; Waseda types.

We focus on the triple points. Here Waseda /10/ has identified three $S(q)$ types, mainly via the principal peak shapes (Fig. 3), and their distribution throughout the Periodic Table is as in Fig. 4. The sec. (ii) description for $\mathrm{Rb}$ offers an explanation for other type a cases which appears to be correct (see below) for groups $1 \mathrm{~A}$ and $2 \mathrm{~A}$ (excluding $\mathrm{Be}$ ). An explanation $19,6 /$ for the others (although not the only one mooted) is that tails are essentially repulsive (eg. as used in (7)). Such a feature has been shown to underlie (depending upon detail) not only cases of type $\mathrm{b}$ and $\mathrm{c}$, but also some of type a such as $\mathrm{Pb} / 8,9 /$.

This viewpoint is consistent with recent systematically calculated pseudopotential results $/ 10 /$ (Fig. 5) which, although inevitably open to quantitatative revision, have the right general forms. For example, the pronounced minima in groups $1 \mathrm{~A}$ and $2 \mathrm{~A}$ are consistent with the observed closer packing in the solids while the loss of minimum allows possible, but not inevitable (cf. $\mathrm{Pb}$ ), destablisation to more open structures. Also, for liquids, as we have seen, such curves are suitable for explaining the Waseda classification. A detailed study $/ 11 /$ lends credence to this view.

\section{(iv) Low $\mathrm{g}$ limit of structure factors}

We next show how the $S(0)$ values of Fig. 4 are qualitatively understood. Consider a reference fluid of hard sphere cores; then the attractivetail perturbations(Fig.5) of the $1 \mathrm{~A}, 2 \mathrm{~A}$ elements enhance

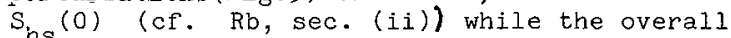

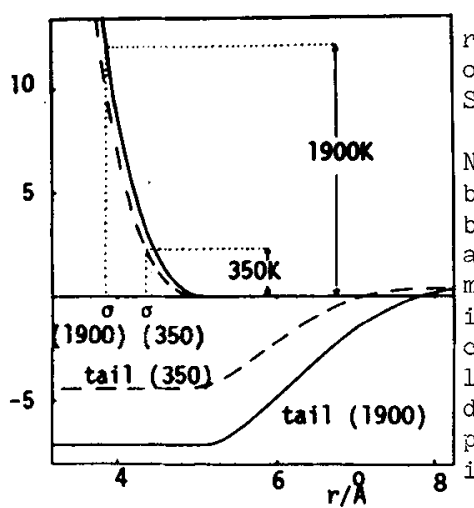
repulsive character of the others suppress it. Scrutiny of the data (Fig. 4) and the curves (Fig. 5) suggest $S_{\text {hs }}(0) \approx 0.020$ and it remains to understand this number.

Now the Gibbs-Bogoliubov method replaces the actual core by a truly 'all purpose' hard sphere with diameter given by $/ 12 / \mathrm{v}$ cope $(\sigma) \approx \mathrm{k}_{\mathrm{B}} \mathrm{T}$. This implies $\sim 45 \%$ packing and $S(0) £ 06$ :028 - too large! But the subtier WCA method yields a 'squashy' sphere characterised essentially by a diameter $\sigma$ and a force $v^{\prime}$ ine $(\sigma) / 4 /$. The criterion for $\sigma$ becomes $v$ (o) $\approx \mathrm{k}_{\mathrm{T}}^{\mathrm{T}} \mathrm{v}$ and the larger value thus produced combines with the force to describe $S(q)$ generally. However $\sigma$ alone is appro.

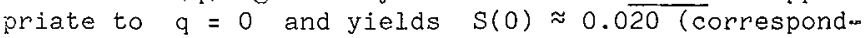
ing to an apparent packing $(\mu / 6)$ no $3 \approx 0.50$.

Fir. 2 .. Core and tails (in mRy) for $\mathrm{Rb}$ at $350 \mathrm{~K}$ ( $\mathrm{i} .46$ $\left.8 \mathrm{~cm}^{-3}\right)$ and $1500 \mathrm{~K}(0.64$ $\left.8 \mathrm{~cm}^{-3}\right) / \bar{s} /$.

This account of $S(0)$ bears closer analysis, e.g. the increasing attractiveness of the tail (Fig. 5) through the sequence $\mathrm{Hg}$. $\mathrm{Cd}, \mathrm{Zn}, \mathrm{Mg}$, Ca, $\mathrm{Sr}, \mathrm{Ba}$ is reflected in the $S(0)$ trend in Fis. 4 ( $\mathrm{Sr}$ being, perhaps, a minor exception). Other correct trends are discernable but numerical uncertainity suggests caution at this point.

III - BINAFY MIXTURES

\section{(i) Generalities}

Consider a mixture of atoms, the partial number densities being $n_{i} \equiv c_{i} n$, where $c_{1}=c$ and $c_{2}=1-c$ are the concentrations. Then (1) generalises to 


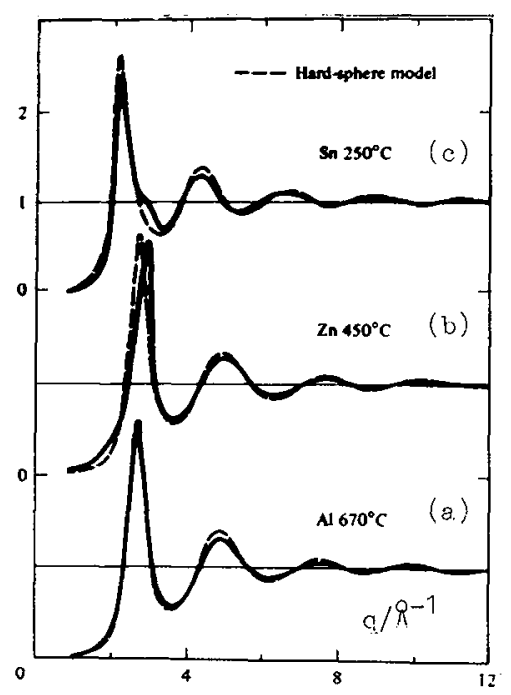

\begin{tabular}{|c|c|c|c|c|c|}
\hline $1 \mathrm{~A}$ & $2 \mathrm{~A}$ & $2 B$ & 3 & 4 & 5 \\
\hline $\begin{array}{lr}\mathrm{Li} & \mathrm{BCC} \\
\mathrm{a} & 0.028\end{array}$ & Be $\quad$ HCP & & $\overline{\mathrm{B}}$ & & \\
\hline $\begin{array}{lr}\mathrm{Na} & \mathrm{BCC} \\
\mathrm{a} & 0.023\end{array}$ & $\begin{array}{|lr|}\mathrm{Mg} & \mathrm{HCP} \\
\mathrm{a} & 0.025\end{array}$ & & \begin{tabular}{|lr}
$\mathrm{AI}$ & $\mathrm{FCC}$ \\
$\mathrm{a}$ & 0.017
\end{tabular} & $\begin{array}{l}\mathrm{Si} \\
\mathrm{c}\end{array}$ & $\mathrm{P}$ \\
\hline $\begin{array}{lr}\mathrm{K} & \mathrm{BCC} \\
\mathrm{a} & 0.023 \\
\end{array}$ & $\begin{array}{|lr|}\mathrm{Ca} & \text { FCC } \\
\mathrm{a} & 0.035 \\
\end{array}$ & 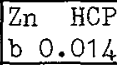 & \begin{tabular}{|lr} 
Ga & ORC \\
c & 0.005 \\
\end{tabular} & $\begin{array}{l}\mathrm{Ge} \\
\mathrm{c}\end{array}$ & As \\
\hline $\begin{array}{lr}\mathrm{Rb} & \mathrm{BCC} \\
\mathrm{a} & 0.022\end{array}$ & $\begin{array}{|lr|}\text { Sr } & \text { FCC } \\
2 & 0.031\end{array}$ & \begin{tabular}{|ll}
$\mathrm{Cd}$ & $\mathrm{HCP}$ \\
$\mathrm{b}$ & 0.012
\end{tabular} & $\begin{array}{lr}\text { In } & \text { TET } \\
\mathrm{a} & 0.007\end{array}$ & $\begin{array}{lr}\text { Sn } & \text { TET } \\
\text { C } & 0.007\end{array}$ & \begin{tabular}{|lr}
$\mathrm{Sb}$ & $\mathrm{RHL}$ \\
$\mathrm{c}$ & 0.019
\end{tabular} \\
\hline $\begin{array}{lr}\text { Cs } & \text { BCC } \\
\mathrm{a} & 0.024 \\
\end{array}$ & $\begin{array}{ll}\mathrm{Ba} & \mathrm{BCC} \\
\mathrm{a} & 0.036\end{array}$ & \begin{tabular}{|lll}
$\mathrm{Hg}$ & $\mathrm{RHL}$ \\
$\mathrm{b}$ & 0.005
\end{tabular} & $\begin{array}{lr}\mathrm{T} 1 & \mathrm{HCP} \\
\mathrm{a} & 0.011\end{array}$ & $\begin{array}{lr}\mathrm{Pb} & \mathrm{FCC} \\
\mathrm{a} & 0.009\end{array}$ & \begin{tabular}{|ll}
$\mathrm{Bi}$ & RHI \\
$\mathrm{c}$ & 0.010
\end{tabular} \\
\hline
\end{tabular}

Fig. 4(above) - Solid (room T) and liquid structures; also $S(0)$ at melting from eq. (2) and observed data. Some solid structures vary with $T$ but the distinction between closer and looser packing persists.

Fig. 3(left) - Waseda $S(q)$ types: (a) hard sphere, (b) skew peak, (c) shouldered peak.
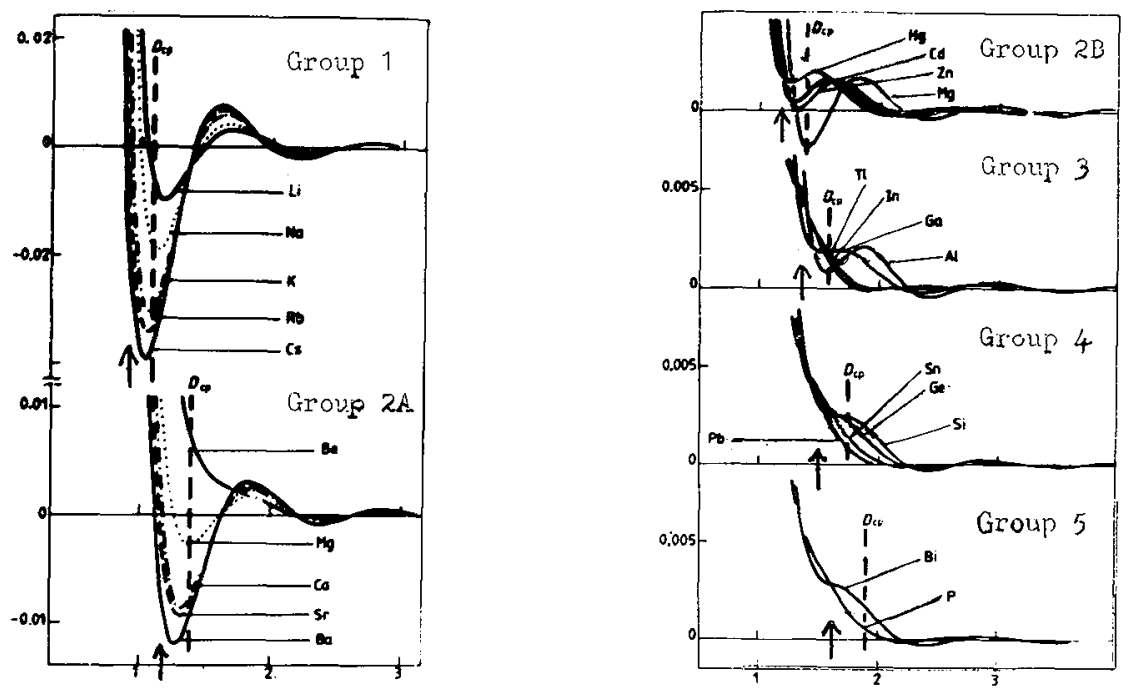

Fig. 5 - Hafner-Heine potentials (energies: $z^{2} e^{2} / R_{a} ;$ lengths: $\pi / k_{F}$ ). $D_{\text {ep }}=$ interatomic distance in close packed solid. Arrows denote liquid statê diaméters for $45 \%$ - $50 \%$ packing (scarcely distinguishable on this scale).

$$
\tilde{S}_{i j}(q)=\left(n_{i} n_{j}\right)^{\frac{1}{2}} \int\left\{g_{i j}(r)-1\right\} \exp (\underset{\sim}{i} \cdot \underset{\sim}{r}) d r
$$

where $\tilde{S}_{i j}=S_{i j}-\delta_{i j}$, and $(3)$ becomes

$$
h_{i j}(r)=c_{i j}(r)+\left[n_{k} \int h_{i k}\left(\left|\underset{\sim}{r}-\underset{\sim}{r}{ }^{\prime}\right|\right) c_{k j}\left(r^{\prime}\right) d{\underset{\sim}{r}}^{\prime},\right.
$$

where $h_{i j}=g_{i j}-1$, and the $c_{i j}$ so defined satisfy (cf. (5))

$$
c_{i j}(r) v-v_{i j}(r) / k_{B} T \text { (large } r \text { ). }
$$


Eqs. (9) transform (cf. (4)) to

$$
\tilde{S}_{i j}(q)=\left(n_{i} n_{j}\right)^{\frac{1}{2}} c_{i j}(q)+\sum\left(n_{k} n_{j}\right)^{\frac{1}{2}} \tilde{s}_{i k}(q) c_{k j}(q) \text {. }
$$

Often, one stresses the concentration variable, c/13/. Consider $/ 14 /$

$$
g_{c c}(r) \equiv c_{1}^{2} c_{2}^{2}\left\{g_{11}(r)+g_{22}(r)-2 g_{12}(r)\right\}
$$

which governs the concentration fluctuations; it is species-sensitive and indicates (by size and sign) the 'chemical short range order'. The corresponding structure factor is

$$
\mathrm{S}_{\mathrm{cc}}(q) \equiv c_{1} c_{2}+\mathrm{n} \int \mathrm{g}_{\mathrm{cc}}(\mathrm{r}) \exp (\mathbf{i q} \cdot \mathbf{r}) \text {, }
$$

for which (cf. (2)) there is a thermodynamic limit /13/

$$
\mathrm{S}_{C \mathrm{C}}(0)=\mathrm{Nk}_{\mathrm{B}} \mathrm{T} /\left(\partial^{2} \mathrm{G} / \partial \mathrm{c}^{2}\right)_{\mathrm{P}, \mathrm{T}, \mathrm{N}},
$$

$N$ being the total number of ions and $G$ the Gibbs free energy.

Eq. (13) connects, via (12) and (8), to the $c_{i j} / 13 /$ to give

$$
s_{c c}^{-1}(q)=\left(c_{1} c_{2}\right)^{-1}-n\left\{c_{11}(q)+c_{22}(q)-2 c_{12}(q)\right\}-f(q)
$$

where $f=f\left(c_{j i}\right)$ is simple but longish so is not given here. Eq. (15) is the analogue of (4) and yields (cf. (6))

$$
S_{c c}(q)=S_{c c}(0) /\left(1+\xi_{c}^{2} q^{2}\right) \quad(\text { Low } q)
$$

Just as $S(0)$ diverges at $T$, so does $S(0)$ at phase separation (PS) and $S^{-1}(0)$ on compound formation (CF). If $S_{c c}(0)^{c c}$ is large (small) we have a PS(CF)
tendency.

(ii) $\mathrm{S}_{\mathrm{cc}}(\mathrm{q})$ for some binary alloys

Fig. 6 shows three measured $/ 14 / \mathrm{S}(q)^{\prime} \mathrm{s}$. That for the Ca alloy is close to hard sphere form (oscillating; near $c_{1} c_{2}$ ) with diameters quite well decided externally

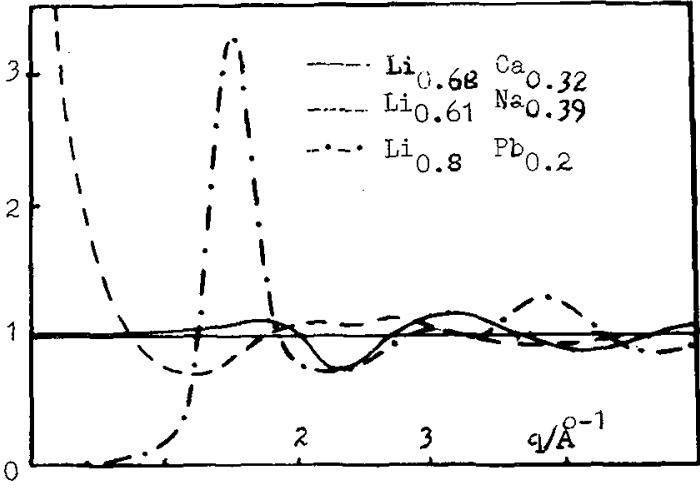

Fig. $6-S_{c c}(q) / c_{1} c_{2}$ for the three alloys near melting

$(q) \approx f(q) / 13,15 /$ and $s_{c c}^{c o r e}(q) \quad c_{1} c_{2}$ to obtain

$$
n \tilde{v}_{\text {ord }}(q) \approx \frac{1}{2} k_{B} T\left\{\left(c_{1} c_{2}\right)^{-1}-S_{c c}^{-1}(q)\right\} \text {. }
$$
from pure liquid considerations. The others illustrate PS and CF tendencies; to interpret, we identify cores and tails and, in RPA (cf. (7)), write

$c_{i j}(r)=c_{i j}^{\text {core }}(r)-n v_{i j}^{t a i l}(r) / k_{B} T(17)$ and find $S_{c c}(q)$ from (15). The result is governed by an ordering potential

$\mathrm{v}_{\text {ord }}=\mathrm{v}_{12}^{\mathrm{tail}}-\frac{1}{2}\left\{\mathrm{v}_{11}^{\mathrm{tail}}+\mathrm{v}_{22}^{\mathrm{tail}}\right\}$

When, predominantly $v_{\text {ord }} \gtrless 0$, like (unlike) neighbour coordination is preferred and there is a PS(CF) tendency. This rule emerges by using $(17),(18)$ in (15) and writing $\mathrm{f}_{\text {core }}$

The general character described above follows when $q=0$. 
$A b$ initio calculation of the $v_{i j}$ is risky both intrinsically (electron theory uncertainty) and because of error ${ }^{i j}$ accumulation in (18). Instead Ratti and Bhatia /16/ chose hard sphere cores without tails for like ions, so $v_{12}=v_{\text {ord }}$, by (18),

$$
v_{\text {ord }}(r)=\left\{\begin{array}{cc}
A & \left(r<\sigma_{12}\right) \\
A\left(\sigma_{12} / r\right) \exp \left\{-\lambda\left(r-\sigma_{12}\right)\right\} & \left(r>\sigma_{12}\right)
\end{array}\right.
$$

With diameters externally specified and (arbitrarily) $\lambda=\sigma_{12}^{-1}$, the single adjusted parameter $A=3.7 \times 10^{-3} \mathrm{eV}$ accounts reasonably for Li - Ná in Fig. 6. Conversely, transformation of (19) using observed data for $\mathrm{Li}_{0.8} \mathrm{~Pb}_{0.2}$ leads /15/ to a similar picture with $A \approx-0.4 \mathrm{eV}, \lambda=1.1 \AA$ and $\sigma_{12} \approx 3 \AA$ (externally required and internally satisfied).

(iii) Low q limit of $\mathrm{s}_{\mathrm{cc}}(q)$

As in II(iv), $q=0$ is of interest and some thermodynamically measured data are shown in Fig. 7. ( $\mathrm{Na}-\mathrm{Cs}$ is substituted for $\mathrm{Li}-\mathrm{Na}$ since results for the latter

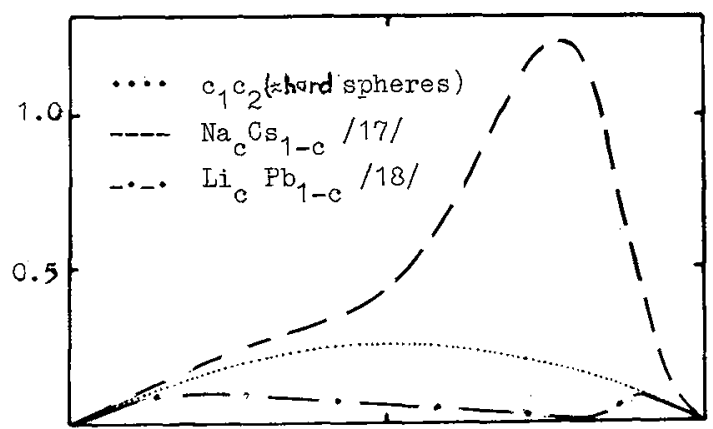

Fig. 7 - $S$ (0) versus c. Ref. /18/ dati? interpolatę by present writer. are not known). Only $\mathrm{v}_{\text {ord }} \equiv \int_{\mathrm{v}}(\mathrm{r}) \mathrm{dr}$, rather than the detail of $(20), \tilde{i s}$ needed and one finds that fixed externally prescribed diameters and $\tilde{v}=3.7 \mathrm{eV} \AA^{3}$
describes the whole curve quite well. But such a parametrisation fails for $\mathrm{Li}-\mathrm{Pb}$; e.g. the $\mathrm{v}$ required at $c=0.5$ is $<20 \%$ of the at $0.8 / 19 \%$.

The above, unfortunately, lacks a dependable electron basis. Pseudopotential theory, quite successful in $\$ 2$ formally applies to alloys but, even if valid, the errors in finding the $v_{i j}$ accumulate in $v_{\text {ord }}$. Here, clearly, muth remains to be arone.

Acknowledgements I am grateful to my colleagues and coworkers for their influence on this work, to SERC for its support and to Mrs. A. Steven for typing this difficult manuscript.

\section{REFERENCES}

/1/ Franz, G., Freyland, W., Gläser, W., Hensel, F. and Schneider, E., J. Physique C8 41 (1980) 194 .

/2/ Weeks, J.D., Chandler, D. and Anderson, H.C., J.Chem.Phys. 54 (1971) 5237.

/3/ McLaughlin, I.I. and Young, W.H., J.Non-Cryst. Sol. 61 \& 62 (1984) 89.

/4/Meyer, A., Silbert, M. and Young, W.H., Phys.Chem.Liq. 13 (1984) 293

/5/ Evans, E. and Sluckin, T., J. Phys. C 14 (1981) 2569, 3137 .

/6/ McLaughlin, I.I. and Young, W.H., Phys. Chem.Liq. 11 (1982) 263.

/7/ Meyer, A., Silbert, M. and Young, W.H. Phys.Chem.Liq. 14 (1984) 1.

/8/ Waseda, Y., The Structure of Non-Crystalline Materials (McGraw-Hill, New York, 1980), pp 56, 62.

/9/ Silbert, M. and Young, W.H., Phys. Lett. 58A (1976) 469.

/10/ Hafner, J. and Heine, V., J. Phys. F 13 (1983) 2479.

$111 /$ Hafner, J. and Kahl, G., J. Phys. F $1 \frac{13}{4}(1984) 2259$.

/12/ Silbert, M. and Young, W.H., J.Phys. C 14 (1981) 2425.

/13/ Bhatia,A.B. and Thornton, D., Phys. Rev. B2 (1970) 3004; Bhatia, A.B., Liquid Metals 1976, Conf. Series No.30, Inst. of Fhys., Bristol (1977) p. 21.

$114 /$ Chieux, P. and Ruppersberg, H., J. Physique C8 41 (1980) 145 .

/15/ Copestake, A.P., Evans, R., Ruppersberg, H. and Schirmacher, W., J.Phys. C 13

/16/ Ratti, V.K. and Bhatia, A.B., Nuovo Cim.43B (1978) 1.

/17/ Neale, F.E. and Cusack, N.E., J.Phys.F 12 (1982) 2839.

/18/ Saboungi, M.L., Marr, M. and Blander, M., J.Chem.Phys.68 (1978) 1375.

/19/ Bowles, R.J. and Silbert, M., J. Phys.F 15 (1985) L105. 